\title{
Combustion of Halogenated Polymers
}

\author{
A. TEWARSON and F. CHU \\ Factory Mutual Research Corporation, Norwood, MA., USA \\ F. H. JIANG \\ University of Science and Technology of China, Hefei, Anhui, China
}

\begin{abstract}
Generalized relationships have been developed between chemical heat of combustion, product yields, corrosion, and equivalence ratio for the halogenated polymers. Results are presented for four fluoro- and five chloropolymers and a polyethylene-polyvinylchloride cable. The chemical heat of combustion and yield of $\mathrm{CO}_{2}$ decrease and yields of $\mathrm{CO}$, hydrocarbons and smoke increase with the halogen content of the polymer. The combustion of the halogenated polymers is very inefficient compared to the non-halogenated polymers and is strongly affected by a slight reduction in the air flow rate. For example, for PVC, increase in the equivalence ratio from 0.40 to 0.60 results in increases in the yields of $\mathrm{CO}$ and smoke by 650 and $260 \%$ respectively and a $29 \%$ decrease in the combustion efficiency. For the non-halogenated polymers, the yields of $\mathrm{CO}$ and smoke do not show any increase until the equivalence ratio reaches values greater than unity.
\end{abstract}

Corrosion in the gas phase is quantified in terms of a corrosion parameter. The corrosion parameter is insensitive to the generic nature of the halogen atom but is very sensitive to the presence of the hydrogen atom in the chemical structure.

Key words: halogenated polymers, combustion and ventilation, gas phase corrosion, solution corrosion, chemical heat of combustion, yields of combustion products.

\section{INTRODUCTION}

Fluoro- and chloropolymers are commonly used polymers in electrical and electronic components and equipment and in wires and cables as insulation and jacket materials. The fluoro- and chloropolymers are based on the polyethylene structure, where hydrogen atoms are replaced by the halogen atoms. Amongst the chloropolymers, the most widely used polymers are polyvinylchloride ( $\mathrm{PVC})$, polyvinylidene chloride $\left(\mathrm{PVC}_{2}\right)$, neoprene, chlorinated rubber, and chlorinated polyethylenes. PVC, a vinyl $\left(\mathrm{H}_{2} \mathrm{C}=\mathrm{CH}-\right)$ group based polymer, is the most widely used chlorinated polymer. Amongst the fluoropolymers, the commonly used polymers are [1]: 1) tetrafluoroethylene (Teflon, TFE), 2) fluorinated ethylene-propylene ( Teflon, FEP), 3) perfluoroalkoxy (Teflon, PFA), 4) copolymer of ethylene and tetrafluoroethylene (Tefzel, ETFE), 5) copolymer of ethylene and chloro- trifluoroethylene (Halar, ECTFE), 6) chlorotrifluoroethylene (CTFE), 7) polyvinyl fluoride (Tedlar, PVF), and 8 ) polyvinylidene fluoride (Kynar, $\left.\mathrm{PVF}_{2}\right)$.

The halogenated polymers burn with a low heat release rate, because of the presence of the halogen atoms in the structure, and are considered as polymers with low thermal damage expectancy. The major products generated in the combustion of halogenated polymers are 
halogen acids, $\mathrm{CO}, \mathrm{CO}_{2}$, gaseous hydrocarbons, soot, and halogenated organic compounds. The halogen acids, halogenated organic compounds, $\mathrm{CO}$, and soot are responsible for nonthermal damage and halogenated polymers are considered as polymers with moderate to high nonthermal damage expectancy. A recent example of the nonthermal damage is the smoke and corrosion damage caused by the telephone central office fire involving PVC jacketed cables at Hinsdale, Illinois [2].

In our laboratory, we have been studying nonthermal damage due to combustion and pyrolysis products of various polymers including the effect of ventilation [3-5]. A paper was published recently on this study, describing the effects of ventilation on the generation of heat and products for non-halogenated polymers [5]. The effects of ventilation on the combustion of polymers is characterized by the equivalence ratio:

$\Phi=\frac{S \dot{m}_{f}}{\delta \dot{m}_{a}}$

where $\Phi$ is the equivalence ratio, $S$ is the stoichiometric mass air-to-fuel ratio, $\dot{m}_{\mathrm{f}}$ is the fuel mass transfer rate $(\mathrm{g} / \mathrm{s}), \dot{\mathrm{m}}_{\mathrm{a}}$ is the mass air flow rate $(\mathrm{g} / \mathrm{s})$, and $\delta$ is the fraction of air entrained in to the flame under defined conditions ( - ). Combustion with air flow rate greater than required stoichiometrically is defined as the well-ventilated combustion, i.e., $\Phi<1.0$. Combustion with air flow rate less than required stoichiometrically is defined as the ventilationcontrolled combustion, i.e., $\Phi>1.0$.

This paper describes the results of our study on the effects of ventilation on the combustion of the halogenated polymers.

\section{BACKGROUND}

The following relationship has been developed between the heat of combustion, product yields and equivalence ratio [5]:

$f p_{v}=f p_{\infty}\left[1+\frac{\alpha}{\exp (\Phi / \beta)^{-\xi}}\right]$

where $\mathrm{fp}$ is the fire property, $\alpha, \beta$, and $\xi$ are the correlation coefficients characteristic of the chemical structures of the polymers, subscript $v$ represents restricted amount of air and $\infty$ represents infinite amount of air. The fire properties are heat of combustion (or combustion efficiency) and yields (or generation efficiencies) of products. Three conditions can be identified: 1) for $\left.\Phi \gg \beta, \mathrm{fp}_{\mathrm{v}}=\mathrm{fp}_{\infty}(1+\alpha), 2\right)$ for $\Phi \ll \beta, \mathrm{fp}_{\mathrm{v}}=\mathrm{fp}_{\infty}$, and 3) $\Phi \approx \beta$, $\mathrm{fp}_{\mathrm{v}} \approx \mathrm{fp}_{\infty}(1+\alpha / 2.7)$. Thus the parameter $\alpha$ is associated primarily with the magnitude of the fire properties in nonflaming fires ( high $\Phi$ values). The parameter $\beta$ is associated with the fire properties in the transition region between the fires with infinite amount of air and the fires with very restricted amount of air. The parameter $\xi$ is associated with the range of $\Phi$ values for the transition region.

For heat of combustion:

$\frac{\mathrm{fp}_{i, v}}{\mathrm{fp}_{i, \infty}}=\frac{\Delta \mathrm{H}_{\mathrm{i}, \mathrm{v}}}{\Delta \mathrm{H}_{\mathrm{i}, \infty}}=\frac{\Delta \mathrm{H}_{\mathrm{i}, \mathrm{v}} / \Delta \mathrm{H}_{\mathrm{T}}}{\Delta \mathrm{H}_{\mathrm{i}, \infty} / \Delta \mathrm{H}_{\mathrm{T}}}=\frac{\chi_{i, v}}{\chi_{i, \infty}}$ 
where $\Delta \mathrm{H}_{\mathrm{i}}$ is the chemical heat of combustion or its convective or radiative component $(\mathrm{kJ} / \mathrm{g})$, $\Delta \mathrm{H}_{\mathrm{T}}$ is the net heat of complete combustion $(\mathrm{kJ} / \mathrm{g})$, and $\chi_{\mathrm{i}}$ is the combustion efficiency or its convective or radiative component.

For yield of a product:

$\frac{f p_{j, v}}{f p_{j, \infty}}=\frac{y_{j, v}}{y_{j, \infty}}=\frac{y_{j, v} / \Psi_{j}}{y_{j, \infty} / \Psi_{j}}=\frac{\eta_{j, v}}{\eta_{j, \infty}}$

where $y_{j}$ is the yield of product $\mathrm{j}(\mathrm{g} / \mathrm{g}), \Psi_{\mathrm{j}}$ is the stoichiometric yield for the maximum possible conversion of the fuel to the product, $\eta_{j}$ is the generation efficiency of the product and subscript $\mathrm{j}$ represents the product. The stoichiometric yield is defined as:

$\Psi_{j}=\frac{v_{j} M_{j}}{M_{f}}$

where $v_{j}$ is the stoichiometric coefficient of product $\mathbf{j}, \mathbf{M}_{\mathrm{j}}$ and $\mathrm{M}_{\mathrm{f}}$ are the molecular weights of the product and the fuel in $g /$ mole respectively.

The values of the fuel mass transfer rate, mass flow rate of air, heat of combustion, and yields of products are determined in the experiments. The value of the stoichiometric yield is derived from the known or measured fuel elemental composition. The value of the net heat of complete combustion is derived from the heat of formation of the fuel and the products or is measured in the Oxygen Bomb Calorimeter (data corrected for water as a gas). The values for the stoichiometric yield and net of complete combustion, derived in this fashion for the fluoroand chloro-polymers, are listed in Table 1.

TABLE 1. Net Heat of Complete Combustion and Stoichiometric Yields of Major Products for Fluoro- and Chloropolymersa

\begin{tabular}{|c|c|c|c|c|c|c|c|c|c|}
\hline Polymer & Formula & $\Delta \mathrm{H}_{\mathrm{T}}$ & $\Psi_{\mathrm{co}}$ & $\Psi_{\mathrm{co} 2}$ & $\Psi_{\mathrm{H} 2 \mathrm{O}}$ & $\Psi_{\mathrm{hc}}$ & $\Psi_{\mathrm{s}}$ & $\Psi_{\mathrm{HF}}$ & $\Psi_{\mathrm{HCl}}$ \\
\hline \multicolumn{10}{|l|}{ Fluoropolymers } \\
\hline PVF-41\%F & $\mathrm{CH}_{1.5} \mathrm{~F}_{0.50}$ & 13.5 & 1.22 & 1.91 & 0.59 & 0.59 & 0.52 & 0.44 & 0.00 \\
\hline $\mathrm{PVF}_{2} .59 \% \mathrm{~F}$ & CHF & 13. & 0.88 & 1.38 & 0.28 & 0.41 & 0.38 & 0.63 & 0.00 \\
\hline ETFE-59\% & $\mathrm{CH}_{1.01} \mathrm{~F}_{0.99}$ & 12.6 & 0.88 & 1.38 & 0.29 & 0.41 & 0.38 & 0.62 & 0.00 \\
\hline ECTFE-64\%F & $\mathrm{CHF}_{0.75} \mathrm{Cl}_{0.25}$ & 12.0 & 0.78 & 1.22 & 0.25 & 0.36 & 0.33 & 0.42 & 0.25 \\
\hline PFA-71\%F & $\mathrm{CF}_{1.6} \mathrm{O}_{0.01}$ & 5.0 & 0.66 & 1.00 & 0.00 & 0.00 & 0.28 & 0.00 & 0.00 \\
\hline FEP-74\%F & $\mathrm{CF}_{1.8}$ & 4.8 & 0.61 & 0.95 & 0.00 & 0.00 & 0.26 & 0.00 & 0.00 \\
\hline TFE-76\%F & $\mathrm{CF}_{2}$ & 6.2 & 0.56 & 0.88 & 0.00 & 0.00 & 0.24 & 0.00 & 0.00 \\
\hline CTFE-79\% Cl & $\mathrm{CF}_{1.5} \mathrm{Cl}_{0.50}$ & 5.0 & 0.48 & 0.76 & 0.00 & 0.00 & 0.21 & 0.00 & 0.00 \\
\hline \multicolumn{10}{|c|}{ Chloropolymers } \\
\hline PE-0\% C1 & $\mathrm{CH}_{2}$ & 43.6 & 2.00 & 3.14 & 1.29 & 1.00 & 0.86 & 0.00 & 0.00 \\
\hline $\mathrm{PE}-25 \% \mathrm{Cl}$ & $\mathrm{CH}_{2} \mathrm{Cl}_{0.13}$ & 31.6 & 1.51 & 2.37 & 0.97 & 0.76 & 0.65 & 0.00 & 0.25 \\
\hline $\mathrm{PE}-36 \% \mathrm{Cl}$ & $\mathrm{CH}_{2} \mathrm{Cl}_{0.22}$ & 26.3 & 1.29 & 2.03 & 0.83 & 0.65 & 0.55 & 0.00 & \\
\hline Neoprene-40\% Cl & $\mathrm{CH}_{1.25} \mathrm{Cl}_{0.25}$ & 25.0 & 1.27 & 2.00 & 0.51 & 0.60 & 0.55 & 0.00 & 41 \\
\hline $\mathrm{PE}-42 \% \mathrm{Cl}$ & $\mathrm{CH}_{2} \mathrm{Cl}_{0.29}$ & 23.5 & 1.16 & 1.82 & 0.75 & 0.58 & 0.50 & 0.00 & 0.43 \\
\hline $\mathrm{PE}-48 \% \mathrm{Cl}$ & $\mathrm{CH}_{2} \mathrm{Cl}_{0.36}$ & 20.6 & 1.05 & 1.65 & 0.68 & 0.53 & 0.45 & 0.00 & 0.49 \\
\hline PVC-56 \% Cl & $\mathrm{CH}_{1.5} \mathrm{Cl}_{0.50}$ & 16.4 & 0.90 & 1.42 & 0.44 & 0.44 & 0.39 & 0.00 & \\
\hline & & & 0.58 & 0.92 & 0.19 & 0.27 & 0.25 & 0.00 & \\
\hline
\end{tabular}

a: subscript hc-total gaseous hydrocarbons; s: smoke ; net heat of complete combustion in kJ/g. 
The stoichiometric yield and net heat of complete combustion are sensitive to the number of hydrogen and halogen atoms relative to the carbon atom in the polymers and provide a reasonable insight into the relative amounts of heat and products and the chemical nature of the products expected to be generated from the combustion of the polymers.

The stoichiometric yield also provides an insight into the corrosion behavior of the products, as halogen acids in the presence of water are generally the dominant products responsible for corrosion. For example, no HF is generated from PFA, FEP, TFE, and CTFE, thus no corrosion is expected from the combustion products of these polymers, unless water is available from the environment and there is hydrolysis of the organo-fluorinated compounds. For PVF, $\mathrm{PVF}_{2}$, ETFE, ECTFE, and all the chlorinated polymers, $\mathrm{HF}, \mathrm{HCl}$, and water are generated, thus corrosion would be expected from the combustion products of these polymers even in a dry environment.

\section{EXPERIMENTS}

\section{Polymers}

The following halogenated polymers were examined in the study: TFP, FEP, PFA, ETFE, ECTFA, and PE with $0,25,36,42$, and $48 \%$ by weight of chlorine, PVC ( $56 \%$ by weight of chlorine), and a cable with PE insulation and PVC jacket (PE-PVC).

\section{Apparatus}

The experiments were performed in the Factory Mutual Research Corporation (FMRC) Flammability Apparatus (50 kW-Scale) shown in Fig. 1. The Apparatus consists of a lower and an upper section. The lower section was used to perform the combustion experiments. The upper section was used to quantify the heat of combustion (or the combustion efficiency) and the yields (or generation efficiencies ) of the products and corrosion in the gas phase and in the water solution. Details of the Apparatus, experimental procedures, and calculations are given in Refs. 3-5.

\section{Equivalence Ratio}

The equivalence ratio was quantified in the lower section of the Apparatus.

PVC was used in the form of a $23 \mathrm{~mm}$ thick horizontal circular slab, $95 \mathrm{~mm}$ in diameter. Other halogenated polymers were used in the granular or powdered form. The PE-PVC cable was used in $95 \mathrm{~mm}$ lengths. Each polymer or the cable was contained in a $100 \mathrm{~mm}$ diameter and 25 $\mathrm{mm}$ deep thin walled aluminum dish and placed on a platform inside an air tight quartz tube, $162 \mathrm{~mm}$ in diameter and $432 \mathrm{~mm}$ in length with a $260 \mathrm{~mm}$ long aluminum extension. The samples were exposed to external heat fluxes in the range of 20 to $60 \mathrm{~kW} / \mathrm{m}^{2}$. Air with mass flow rates in the range of 1.4 to $4.2 \mathrm{~g} / \mathrm{s}$ was introduced at the bottom of the tube.

The fuel mass transfer rate and mass air flow rate were measured every second. The fraction of air entrained into the flame was about 0.80 [5], which was used in the calculation of the equivalence ratio from Eq. 1.

\section{Chemical Heat of Combustion and Yields of Products}

The chemical heat of combustion and yields of products were quantified in the upper section of the Apparatus.

All the fire products were captured, along with ambient air, in the sampling duct, where measurements were made for the gas temperature, flow rate of product-air mixture through the duct at the gas temperature, and volume fractions of $\mathrm{CO}, \mathrm{CO}_{2}$, hydrocarbons, and $\mathrm{O}_{2}$ using 
gas analyzers. The soot volume fraction was obtained from the optical measurements, as described in Ref. 5. The generation rates of the products were calculated from the volume fractions, densities of the products and air, and total volumetric flow rate of product-air mixture through the duct as described in Ref. 5 . The chemical heat release rate was calculated from the generation rates of $\mathrm{CO}$ and $\mathrm{CO}_{2}$ and consumption rate of $\mathrm{O}_{2}$, also as described in Ref.5. The chemical heat of combustion was determined from the ratio of the cumulative chemical heat release rate to the cumulative fuel mass transfer rate. The yield of each product was determined from the ratio of the cumulative generation rate of the product to the cumulative fuel mass transfer rate.

For the measurement of corrosion in the gas phase and in water, commercially available copper atmospheric and mild steel loop-type of corrosion probes were used respectively. Gas phase corrosion was measured by direct exposure, whereas for corrosion in water, products were deposited on a filter paper located in the product sampling line. The deposit was extracted with a known volume of distilled water and the resulting solution used for the corrosion measurements. The chloride and fluoride ion concentrations in the solution were also measured by specific ion electrodes.
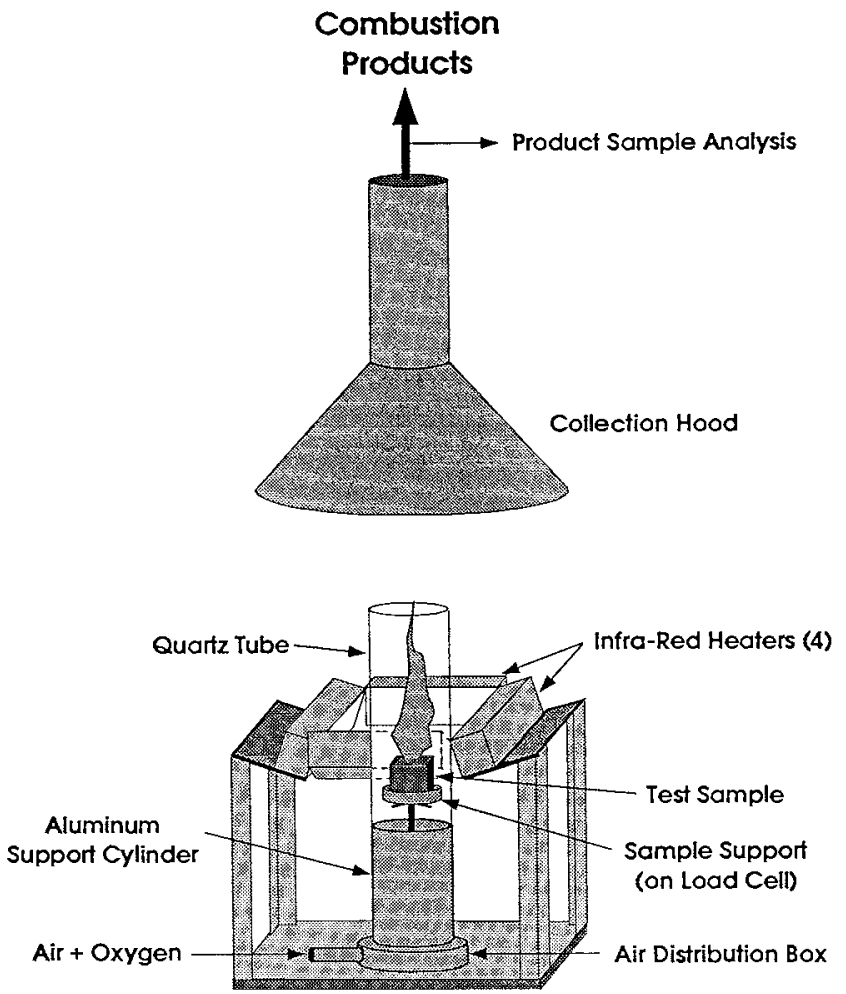

FIGURE 1. The Factory Mutual Research Corporation's Flammability Apparatus (50 kWScale) 


\section{RESULTS}

\section{Well-Ventilated Combustion in Infinite Amount of Air}

The chemical heat of combustion and the yields of $\mathrm{CO}, \mathrm{CO}_{2}$, hydrocarbons and smoke for the combustion of the fluoro- and chloropolymers in infinite amount of air are listed in Table 2. Some of the data in the table are taken from Ref. 6.

TABIE 2. Chemical Heat of Combustion and Yields of Products for the Combustion of the Fluoro- and Chloropolymers Under Infinite Amount of Aira

$$
\text { Polymer } \quad \Delta \mathrm{H}_{\mathrm{ch}}(\mathrm{kJ} / \mathrm{g})
$$

$$
\mathrm{Y}_{\mathrm{j}}(\mathrm{g} / \mathrm{g})
$$

\begin{tabular}{lccccr} 
Fluoropolymers & & $\mathrm{CO}$ & $\mathrm{CO}_{2}$ & hc & Smoke \\
\hline ETFE-59\%F & 5.4 & 0.060 & 0.54 & 0.020 & 0.042 \\
PFA-71\%Fb & 4.7 & 0.097 & 0.37 & $\mathrm{c}$ & 0.002 \\
FEP-74\%Fb & 4.1 & 0.116 & 0.25 & $\mathrm{c}$ & 0.003 \\
TFE-76\%Fb & 4.2 & 0.092 & 0.38 & $\mathrm{c}$ & 0.003 \\
Chloropolymers & & & & & \\
PE-0\%Cl & 38.4 & 0.024 & 2.76 & 0.007 & 0.060 \\
PE-25\%Cl & 22.6 & 0.042 & 1.71 & 0.016 & 0.115 \\
PE-36\%Cl & 10.6 & 0.051 & 0.83 & 0.017 & 0.139 \\
PE-42\%Cl & 8.9 & 0.058 & 0.71 & 0.017 & 0.140 \\
PE-48\%Cl & 7.2 & 0.049 & 0.59 & 0.015 & 0.134 \\
PVC-57\%Cl & 5.7 & 0.063 & 0.46 & 0.023 & 0.172 \\
Cable & & & & & \\
PE-PVC & 12.1 & 0.076 & 0.90 & 0.010 & $\mathrm{c}$
\end{tabular}

aair flow rate: $4.2 \mathrm{~g} / \mathrm{s}$, external heat flux: 20 to $60 \mathrm{~kW} / \mathrm{m}^{2}$, hc: total gaseous hydrocarbons; bexternal heat flux: $60 \mathrm{~kW} / \mathrm{m}^{2} ; \mathrm{c}$ : not measured.

The data in Table 2 show that the chemical heat of combustion and $\mathrm{CO}_{2}$ yield are lower, whereas the $\mathrm{CO}$, hydrocarbons, and smoke yields are higher for the halogenated polymers compared to the parent nonhalogenated polymer (i.e., PE). The combustion of the polymers with the upper limit of the halogen content (FEP and TFE, PVC homopolymer and PE with $\geq$ $36 \%$ of chlorine) is very close to the flame extinction limit as indicated by: 1) the instability in the combustion process noted by the unstable flames with heavy grey/white smoke, and 2) combustion efficiency less than 0.40 (from Tables 1 and 2), a condition found for flame extinction [7]. Such a behavior was also found for the non-halogenated polymers close to the nonflaming region for $\Phi \geq 4$ [5].

The combustion characteristics of the PE-PVC cable resemble the combustion characteristics of the PVC homopolymer rather than the PE homopolymer as indicated by the data in Table 2. This behavior is believed to be due to the retarding effects on PE by the chlorinated compounds generated during PVC combustion.

\section{Well-Ventilated Combustion in Restricted Amount of Air}

Well-ventilated combustion experiments were performed under restricted amount of air for the PVC homopolymer. Since the combustion data for infinite amount of air in Tables 1 and 2 indicate that the combustion of the PVC homopolymer is close to the flame extinction limit, a slight decrease in the equivalence ratio is expected to shift the flaming combustion to nonflaming combustion. This is indicated by the data in Figures 2 to 4 , where the ratios of the chemical heat of combustion and product yields, under restricted and infinite amounts of air, are plotted against the equivalence ratio. In the figures, symbols are the experimental data and 
lines are calculated from the expressions included in the figures, which are based on Eq. 2 with values of $\alpha, \beta$, and $\xi$ for the best fit to the data. The values of these coefficients for $C O$ and smoke are listed in Table 3 along with the coefficients for the nonhalogenated polymers from Ref. 5.

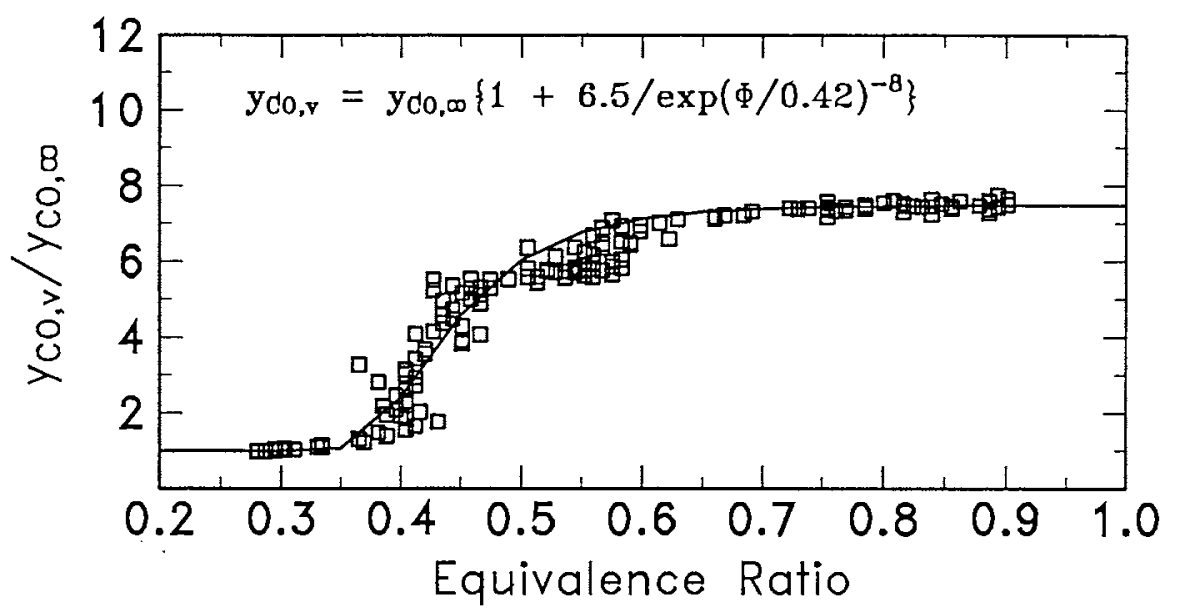

FIGURE 2. Ratio of the Yield of Carbon Monoxide for Restricted and Infinite Amounts of Air Versus the Equivalence Ratio for the Well-Ventilated Combustion of Polyvinylchloride Homopolymer.

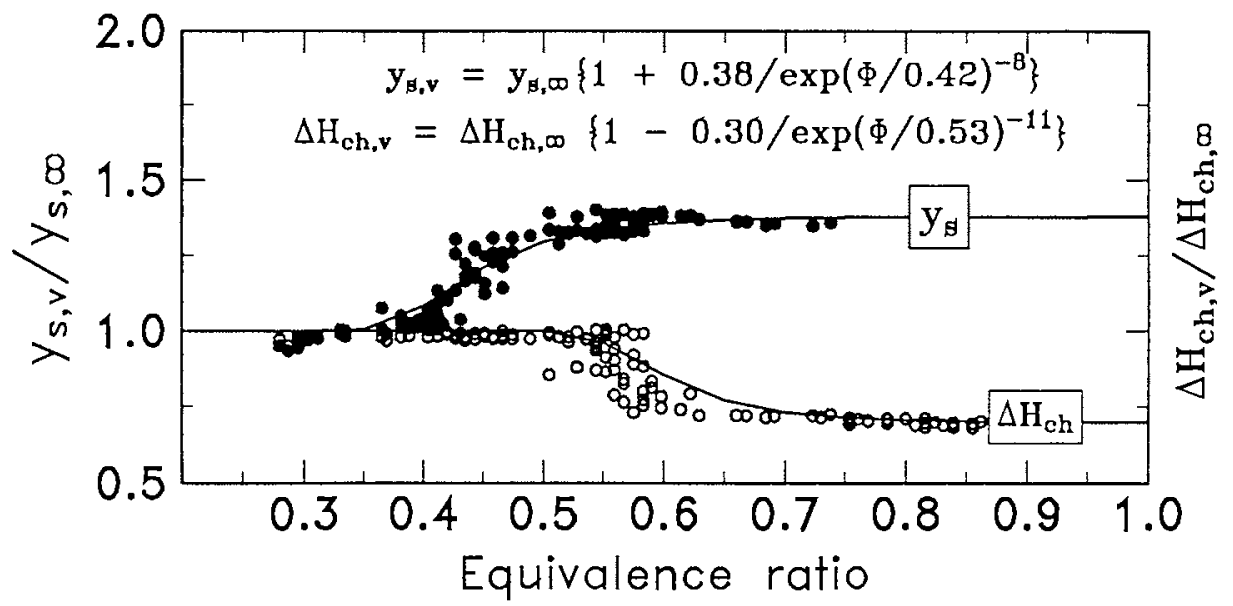

FIGURE 3. Ratios of the Yield of Smoke and Chemical Heat of Combustion for Restricted and Infinite Amounts of Air Versus the Equivalence Ratio for the Well-Ventilated Combustion of Polyvinylchloride Homopolymer. 


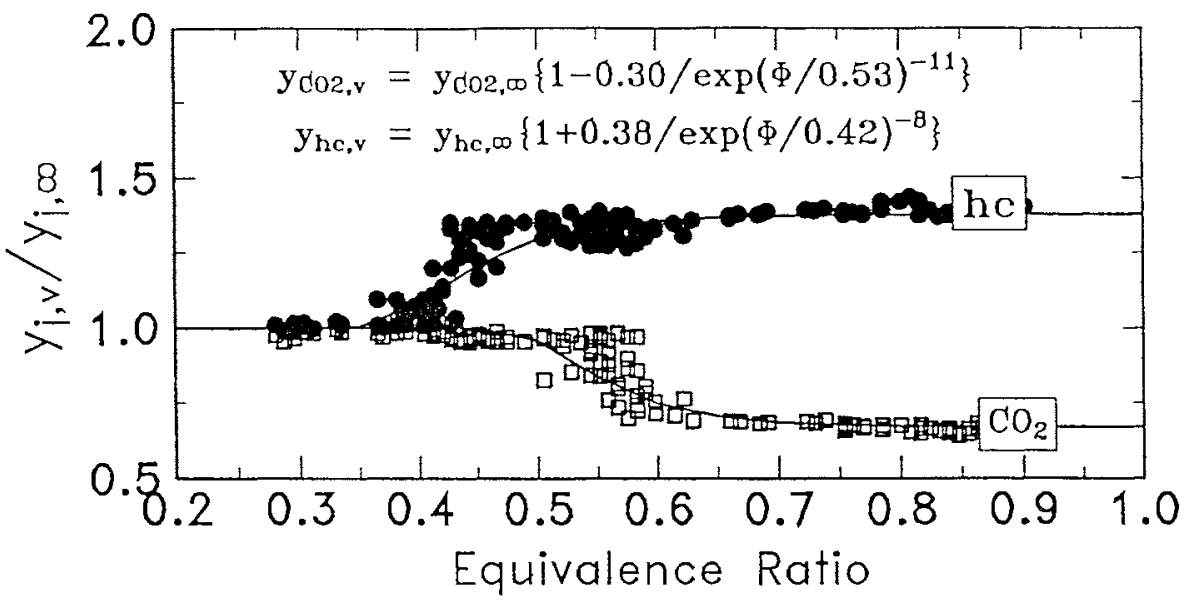

FIGURE 4. Ratios of the Yields of Hydrocarbons and Carbon Dioxide for Restricted and Infinite Amounts of Air Versus the Equivalence Ratio for the Well-Ventilated Combustion of Polyvinylchloride Homopolymer.

In Figs. 2 to 4 , the chemical heat of combustion and yields of $\mathrm{CO}, \mathrm{CO}_{2}$, hydrocarbons, and smoke deviate from the values for infinite amount of air for $\Phi \geq 0.4$, which is significantly lower than the value found for the nonhalogenated polymers ( $\Phi \geq 2.0$ ). For PVC homopolymer, the flaming combustion changes to nonflaming combustion for $\Phi \geq 0.70$, which is also significantly lower than the value found for the nonhalogenated polymers $(\Phi \geq$ 4.0). This is consistent with the highly halogenated nature of PVC and its mode of decomposition. The decomposition of PVC is characterized by the release of $\mathrm{HCl}$, which is initiated at temperature as low as about $100^{\circ} \mathrm{C}$. At a temperature of up to about 200 to $220^{\circ} \mathrm{C}$, $\mathrm{HCl}$ is the major effluent. Presence of oxygen in the air, enhances $\mathrm{HCl}$ release. The generation of $\mathrm{HCl}$ from PVC leads to the formation of double bonds and release of various aromatic/unsaturated hydrocarbons (benzene, ethylene, propylene, butylene, etc).

Figures 5 and 6 show the CO and smoke yields calculated from Eq. (2) with coefficients from Table 3. The data for PVC show that for $0.40 \leq \Phi \leq 1.0$, the maximum $C O$ and smoke yields reach about $60 \%$ of the stoichiometric yields, listed in Table 1 . For non-halogenated polymers, the maximum $\mathrm{CO}$ and smoke yields reach $\leq 30 \%$ of the stoichiometric yields for $\Phi \geq 2.0$. Polystyrene is the only polymer for which the smoke yield exceeds that of PVC. These trends suggest that $\mathrm{CO}$ and smoke are generated much easier from PVC than from the nonhalogenated polymers, possibly due to the formation of double bonds as $\mathrm{HCl}$ is eliminated at temperature as low as $100{ }^{\circ} \mathrm{C}$ from the PVC structure and formation of various compounds with aromatic/unsaturated bonds.

For the non-halogenated polymers considered with $\Phi \geq 4.0$, the CO yield is lowest and the smoke yield is highest for polystyrene, an aromatic ring containing polymer, whereas for polymethylmethacrylate, an aliphatic carbon-hydrogen-oxygen atom containing polymer, the CO yield is highest and smoke yield is lowest. This suggests that aromatic ring structure promotes soot formation, whereas the strong $\mathrm{C}-\mathrm{O}$ bond in the structure remains intact as ventilation is reduced. The affects of reduced ventilation on nonthermal damage are expected to be important; we are, however, not aware of any research in this area, except that of Drysdale 


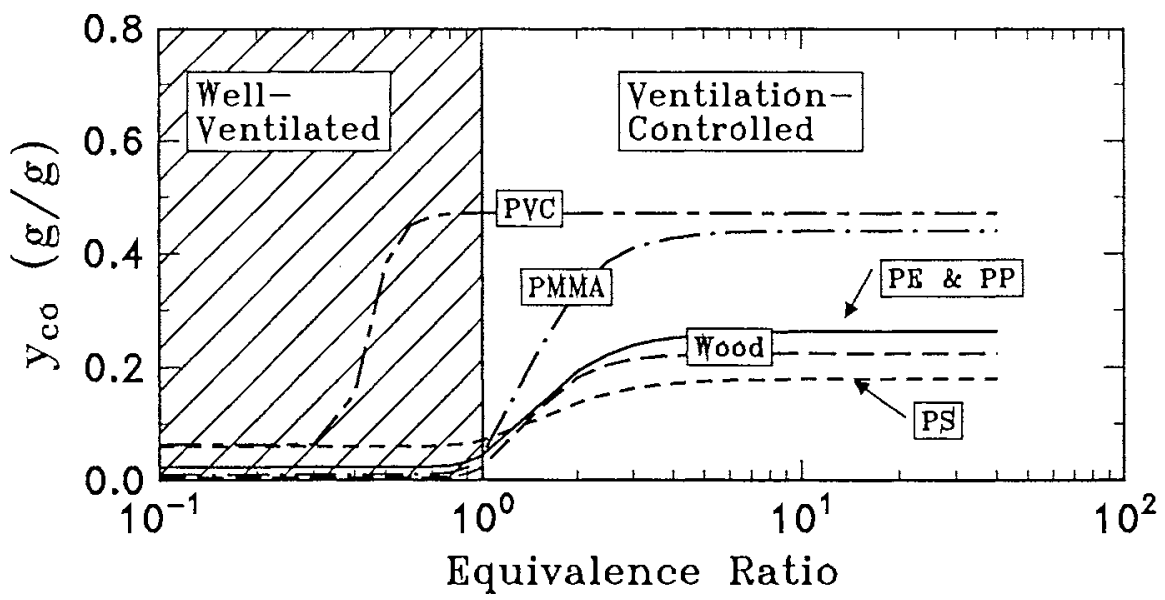

FIGURE 5. Yield of Carbon Monoxide Versus the Equivalence Ratio for the Combustion of Polyvinylchloride Homopolymer and Nongalogenated Polymers.

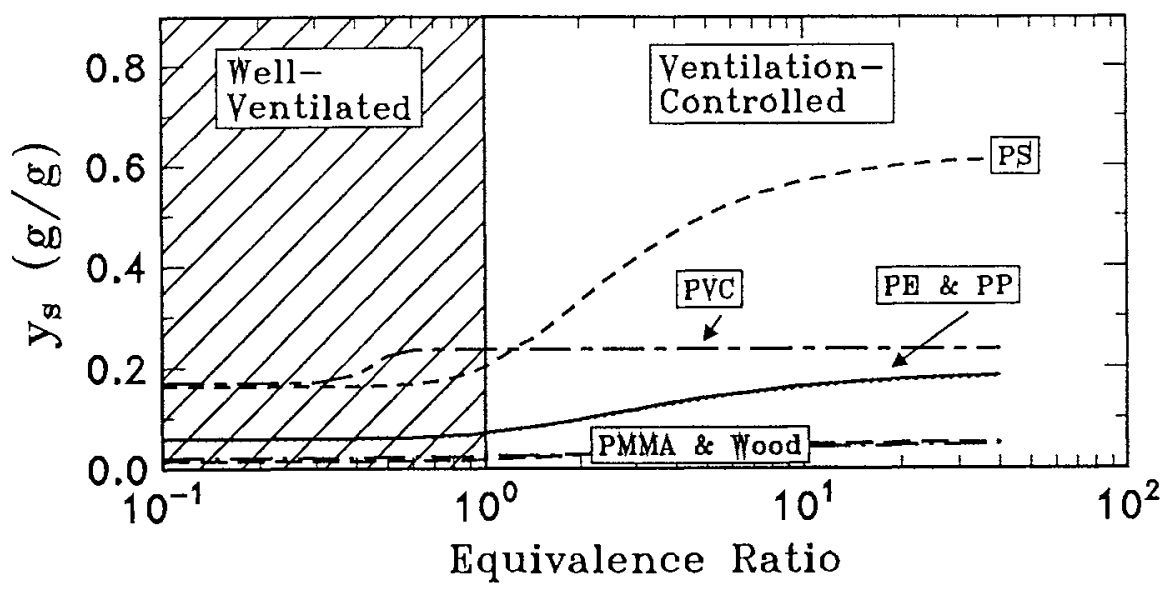

FIGURE 6. Yield of Smoke Versus the Equivalence Ratio for the Combustion of Polyvinylchloride Homopolymer and Nongalogenated Polymers. 
TABLE 3. Yields and Correlation Coefficients for CO and Smoke for PVC Homopolymer and Nonhalogenated Polymers ${ }^{\mathrm{a}}$

\begin{tabular}{|c|c|c|c|c|c|c|c|c|}
\hline \multirow[t]{2}{*}{ Polymer } & \multicolumn{4}{|c|}{$\mathrm{CO}$} & \multicolumn{4}{|c|}{ Smoke } \\
\hline & $\mathrm{y}_{\infty}$ & $\alpha$ & $\beta$ & $\xi$ & $y_{\infty}$ & $\alpha$ & $\beta$ & $\xi$ \\
\hline PVC & 0.063 & 6.5 & 0.42 & 8.0 & 0.172 & 0.38 & 0.42 & 8.0 \\
\hline PS & 0.060 & 2.0 & 1.44 & 2.5 & 0.164 & 2.80 & 2.00 & 1.3 \\
\hline PP & 0.024 & 10.0 & 1.39 & 2.8 & 0.059 & 2.20 & 2.50 & 1.0 \\
\hline PE & 0.024 & 10.0 & 1.39 & 2.8 & 0.060 & 2.20 & 2.50 & 1.0 \\
\hline PMMA & 0.010 & 43.0 & 1.33 & 3.2 & 0.022 & 1.60 & 4.61 & 0.6 \\
\hline Wood & 0.004 & 44.0 & 1.30 & 3.5 & 0.015 & 2.50 & 2.15 & 1.2 \\
\hline Nylon & 0.038 & 36.0 & 1.36 & 3.0 & 0.075 & 1.70 & 3.14 & 0.8 \\
\hline
\end{tabular}

a: Data taken from Ref. 5. PS: Polystyrene; PP: Polypropylene; PE: Polyethylene; PMMA: polymethylmethacrylate.

\section{Gas Phase Corrosion}

The rate of corrosion of surfaces depends on several factors: 1) the nature and concentration of the corrosive products (hydrogen, halogen, and other atoms in the chemical structure of the polymer), 2) moisture content and temperature of air, 3) flow velocity of the fire products-air mixture, and 4) nature, type, and orientation relative to the gas flow of surfaces which come in contact with the products. In this paper, the rate of corrosion in the gas phase is defined by a corrosion parameter:

$\mathrm{k}_{\mathrm{gas}}=\frac{\mathrm{R}_{\text {corr }}}{\left(\dot{\mathrm{m}}_{\mathrm{f}} / \dot{\mathrm{V}}_{\mathrm{T}}\right)}$

where $\mathrm{k}_{\mathrm{gas}}$ is the gas phase corrosion parameter $\left(\AA-\mathrm{m}^{3} / \mathrm{g}-\mathrm{min}\right), \mathrm{R}_{\text {corr }}$ is rate of corrosion $(\AA / \mathrm{min})$, and $\dot{V}_{T}$ is the total volumetric flow rate of the fire product air mixture $\left(\mathrm{m}^{3} / \mathrm{s}\right)$.

For halogenated polymers with hydrogen in the structure, the amount of water generated as well as water available from air will decrease with increase in $\Phi$. Thus the $\mathrm{k}_{\text {gas }}$ is expected to decrease with increase in the $\Phi$ value. This is shown by the data in Table 4 . The corrosion data were measured by exposing a probe to flowing mixture of fire products and air with 0 , $10,20.9$, and $40 \%$ oxygen concentration. The relative humidity of air was $30 \%$ with a temperature of $20^{\circ} \mathrm{C}$.

The data in Table 4 show that the $\mathrm{k}_{\text {gas }}$ values for PE with 25,36 , and $48 \% \mathrm{Cl}$ and PVC are comparable, but $\mathrm{k}_{\text {gas }}$ value for TFE is significantly lower than the chloropolymers, as expected from the HF stoichiometric yield of zero (Table 1) due to the absence of hydrogen atom in the TFE structure. The $\mathrm{k}_{\text {gas }}$ values for the pyrolysis of both PVC and TFE, where water is present in a negligible amount, are significantly lower than the values for the combustion, where water is available in large amounts as it is generated in the combustion as well as present as moisture in the air. 
TABLE 5. Gas Phase Corrosion Parameter for Copper Exposed to Fire Products of Halogenated Polymers ${ }^{\text {a }}$

$\begin{array}{ccccc}\text { Polymer } & \mathrm{O}_{2} & \mathrm{P}^{\mathrm{b}} & \stackrel{\mathrm{C}^{\mathrm{q}}}{\mathrm{q}} & \begin{array}{c}\mathrm{k}_{\mathrm{gas}} \\ (\%)\end{array} \\ & & \left(\mathrm{kW} / \mathrm{m}^{2}\right) & (\AA / \mathrm{min}) /\left(\mathrm{g} / \mathrm{m}^{3}\right)\end{array}$

$\begin{array}{lllll}\mathrm{PE} / 36 \% \mathrm{Cl} & 10.0 & \mathrm{P} & 20 & 0.15 \\ \mathrm{PE} / 48 \% \mathrm{Cl} & 10.0 & \mathrm{P} & 20 & 0.19 \\ \mathrm{PVC} & 10.0 & \mathrm{P} & 20 & 0.15 \\ & 20.9 & \mathrm{C} & 20 & 1.0 \\ \mathrm{PE} / 25 \% \mathrm{Cl} & 10.0 & \mathrm{P} & 50 & 0.14 \\ \mathrm{TFE} & 0.00 & \mathrm{P} & 50 & 0.0036 \\ & 10.0 & \mathrm{P} & 50 & 0.011 \\ & 20.9 & \mathrm{C} & 50 & 0.41\end{array}$

${ }^{a}: \ddot{q}_{\mathrm{e}}$ : external heat flux. ${ }^{\mathrm{b}}$ : P: Pyrolysis; C: combustion,

\section{SUMMARY}

1. A decrease in the amount of air flow by about three times the stoichiometric requirement or below has a strong effect on PVC combustion, resulting in the generation of large amounts of products of incomplete combustion such as $\mathrm{CO}$ and smoke, possibly due to formation of aromatic/unsaturated bonds as $\mathrm{HCl}$ is eliminated from the PVC structure. There is no comparable effect of reduced ventilation on the combustion of non-halogenated polymers.

2. The relationships between chemical heat of combustion or combustion efficiency, yields of products or generation efficiencies and equivalence ratio established in the study and our previous study can be used in models for enclosure fires to assess generation rates of heat and fire products to assess thermal and nonthermal damage and protection requirements.

3. Gas phase corrosion is sensitive to changes in the ventilation, presence of hydrogen in the chemical structures of the polymers, amount of water in the air, and factors affecting hydrolysis of the products. Corrosion in water solution is significantly higher than in the gas phase due to efficient hydrolysis of the fluorocarbon compounds and rapid dissolving of $\mathrm{HCl}$ gas. Corrosion is insensitive to the generic nature of the halogen atoms $\left(\mathrm{Cl}^{-}\right.$and $\left.\mathrm{F}^{-}\right)$.

4. Under highly air-restricted combustion, the yield of $\mathrm{CO}$ is highest from PVC combustion and the yield of smoke is highest from PS combustion, within the polymers examined in the study

\section{NOMENCLATURE}

$\begin{array}{ll}\dot{\mathrm{G}}_{\mathrm{j}} & \text { fire property } \\ \Delta \mathrm{H}_{\mathrm{ch}} & \text { chemeration rate of product } \mathrm{j}(\mathrm{g} / \mathrm{s}) \\ \Delta \mathrm{H}_{\mathrm{T}} & \text { net heat of complete combustion }(\mathrm{kJ} / \mathrm{g}) \\ \mathrm{k} & \text { corrosion parameter }\left(\AA-\mathrm{m}^{3} / \mathrm{min}-\mathrm{g}\right) \\ \dot{\mathrm{m}}_{\mathrm{a}} & \text { mass air flow rate }(\mathrm{g} / \mathrm{s})\end{array}$


$\dot{m}_{\mathrm{f}} \quad$ fuel mass transfer rate $(\mathrm{g} / \mathrm{s})$

M molecular weight ( $\mathrm{g} / \mathrm{mole})$

$\dot{\mathrm{Q}}_{\mathrm{ch}} \quad$ chemical heat release rate $(\mathrm{kW})$

R rate of corrosion ( $\AA / \mathrm{min})$

$\mathrm{S} \quad$ stoichiometric mass air-to-fuel ratio (-)

$\dot{V}_{T}$ total volumetric flow rate of fire product-air mixture $\left(\mathrm{m}^{3} / \mathrm{s}\right)$

$y_{j} \quad$ yield of product $j\left[\int G_{j} d t / \int \dot{m}_{f} d t\right](g / g)$

\section{Greek Symbols}

$\alpha \quad$ correlation coefficient [nonflaming fire] (-)

$\beta \quad$ correlation coefficient [transition region] (-)

$\chi_{\text {ch }} \quad$ combustion efficiency $\left[\dot{Q}_{c h} / m_{f} \Delta H_{T}\right](-)$

$\delta \quad$ fraction of air entrainmented (-)

$\Phi \quad$ equivalence ratio $\left[\mathrm{S} \mathrm{m}_{\mathrm{f}} / \dot{\mathrm{m}}_{\mathrm{a}}\right](-)$

$\eta_{j} \quad$ generation efficieency of product $j\left[\dot{G}_{j} / \dot{m}_{f} \Psi_{j}\right](-)$

$v_{j} \quad$ stoichiometric coefficient of product $j(-)$

$\xi \quad$ correlation coefficient [transition region] (-)

$\Psi_{j} \quad$ stoichiometric yield for maximum possible conversion of fuel to product $(\mathrm{g} / \mathrm{g}$ )

\section{Super/subscript}

$\begin{array}{ll}\text { a } & \text { air } \\ \text { corr } & \text { corrosion } \\ \mathrm{f} & \text { fuel } \\ \mathrm{i} & \text { chemical, convective, radiative } \\ \mathrm{j} & \text { fire product } \\ \mathrm{T} & \text { complete combustion or total } \\ \mathrm{v} & \text { restrtricted amount of air } \\ \infty & \text { infinite amount of air }\end{array}$

\section{REFERENCES}

1. Handbook of Plastics and Elastomers, ed. C.A. Harper, McGraw-Hill Book Company, New York, N.Y., 1975.

2. Isner, M.S., Fire Journal, May/June: 73, 1990.

3. Tewarson, A., J.Fire Sciences, 10: 188-241, 1992.

4. Chu, F.L., "Development and Application of Nonthermal Damage Assessment Techniques", Technical Report J.I.OV1J1.RC, Factory Mutual Research Corporation, Norwood, MA., 1992.

5. Tewarson, A., Jiang, F.H., and Morikawa, T., Combust.Flame, 95: 151-169, 1993.

6. Tewarson, A., in SFPE Handbook of Fire Protection Engineering, pp. 1-179 to 1-199, National Fire Protection Association Press, Quincy, MA., 1988.

7. Tewarson, A., and Khan, M.M., J.Fire Science, 11, 407, 1993.

8. Drysdale, D.D., and Macmillan, J.R., "The Corrosivity of Fire Gases", J.Fire Science, 10, 102, 1992. 